\title{
Pleurodesis with an autologous blood patch to prevent persistent air leaks after lobectomy
}

\author{
Claudio Andreetti, MD, Federico Venuta, MD, Marco Anile, MD, Tiziano De Giacomo, MD, Daniele Diso, MD, \\ Mario Di Stasio, MD, Erino A. Rendina, MD, and Giorgio Furio Coloni, MD
}

Objective: Air leakage after pulmonary lobectomy is a well-known problem often contributing to extended hospitalization. Many techniques have been proposed to prevent and treat air leakage, but none have been proved incontrovertibly effective. We evaluated the role of an autologous blood patch after pulmonary lobectomy.

Methods: Twenty-five patients with air leaks on the sixth postoperative day after lobectomy were enrolled in this study. They were randomly assigned to 2 groups: group A (12 patients), with $50 \mathrm{~mL}$ of autologous blood infused in the pleural cavity; and group B (13 patients), with $100 \mathrm{~mL}$ of blood infused. These 2 groups were retrospectively compared with the last 15 patients showing the presence of air leaks for at least 6 days (group C) (in this group the duration of leakage after the sixth postoperative day was compared). We recorded the duration of posttreatment air leaks and hospitalization.

Results: Air leaks stopped $2.3 \pm 0.6$ days after the procedure in group A, $1.5 \pm 0.6$ days after the procedure in group B, and after $6.3 \pm 3.7$ days in group $\mathrm{C}$. The air leakage disappeared within 72 hours in all patients in groups A and B. There was a statistically significant difference in the duration of drainage between groups $\mathrm{A}$ and $\mathrm{B}(P=.005)$, groups $\mathrm{A}$ and $\mathrm{C}(P=.0009)$, and groups $\mathrm{B}$ and $\mathrm{C}(P=.0001)$, showing the effectiveness of an autologous blood patch, particularly with $100 \mathrm{~mL}$ of blood.

Conclusions: Management of air leaks after lobectomy with an autologous blood patch is easy, safe, and effective, and does not add costs. It may become the gold standard treatment early in the postoperative course.

From the University of Rome "La Sapienza," Department of Thoracic Surgery, Rome, Italy.

Received for publication June 7, 2006; revisions received Sept 29, 2006; accepted for publication Oct 9, 2006.

Address for reprints: Federico Venuta, MD, Cattedra di Chirurgia Toracica, Policlinico Umberto I, Università di Roma "La Sapienza," V.le del Policlinicom 00161 Rome, Italy (E-mail: sofed@libero.it).

J Thorac Cardiovasc Surg 2007;133:759-62 $0022-5223 / \$ 32.00$

Copyright () 2007 by The American Association for Thoracic Surgery

doi:10.1016/j.jtcvs.2006.10.042
$\mathrm{P}$ ersistent air leak after lung resections is a well-known complication experienced by all surgeons in the thoracic community. It is usually managed conservatively with good results, but sometimes a more aggressive approach may be required; however, the length of hospitalization is usually negatively affected. Conservative approaches include a longer period of drainage; physiotherapy; pleurodesis with tetracycline, quinacrine, talcum, or silver nitrate; pneumoperitoneum; and the use of a Heimlich valve. ${ }^{1-7}$ All of these methods have produced encouraging results in selected settings or on a case-by-case basis, but none have definitively solved the problem.

An autologous blood patch has been reported to produce encouraging results in patients with persistent air leakage. ${ }^{8-11}$ However, the real benefit of this method, the amount of blood that should be infused in the pleural cavity, and the timing are still debated. ${ }^{11}$ We designed a prospective study to enroll patients with air leaks after pulmonary lobectomy; the autologous blood patch was performed early during the postoperative course to prevent long-lasting air leaks. The outcome was analyzed after pleurodesis with 2 different amounts of autologous blood ("blood patch") (50 $\mathrm{mL}$ vs $100 \mathrm{~mL}$ ) instilled through the chest tube(s). 


\section{Abbreviations and Acronyms}

$\mathrm{FEV}_{1}=$ forced expiratory volume in 1 second

\section{Patients and Methods}

Twenty-five patients with persistent air leaks after pulmonary lobectomy were prospectively enrolled in this study. All patients underwent lobectomy for non-small cell cancer; they were randomized into 2 groups. Both groups underwent pleurodesis with an autologous blood patch; however, it was performed with $50 \mathrm{~mL}$ of blood in group A (12 patients; age $68.5 \pm 6.9$ years; 7 men $/ 5$ women; forced expiratory volume in 1 second $\left[\mathrm{FEV}_{1}\right] 2.5 \pm 0.8$ $\mathrm{L} / \mathrm{sec})$ and $100 \mathrm{~mL}$ of blood in group $\mathrm{B}$ (13 patients; $65.2 \pm 6.2$ years; 7 men/6 women; $\mathrm{FEV}_{1} 2.4 \pm 0.9 \mathrm{~L} / \mathrm{sec}$ ). Before the blood patch was performed, drainages were kept under moderate suction $(-10 \mathrm{~mm} \mathrm{Hg} /-20 \mathrm{~mm} \mathrm{Hg})$ or alternating suction to waterseal. The procedure was always performed at the patient's bedside and with the residual lobe completely expanded to be able to analyze a homogeneous group of patients. No particular analgesic technique was used. Blood was taken from a vein of the upper arm with a $60-\mathrm{mL}$ syringe and immediately instilled into the pleural cavity through the chest tube(s); 2 instillations were required in group B patients because the syringe had to be refilled once. At the end of the procedure, the chest drainage was flushed with $20 \mathrm{~mL}$ of saline to avoid clotting. After the instillation of blood, the chest tube was left unclamped and kept suspended over a drip stand $60 \mathrm{~cm}$ above the patient's chest; this provided a bend to allow air to exit but prevented blood from leaving the chest cavity. ${ }^{11}$ All patients remained in bed for 40 minutes after pleurodesis; during this time the position of the patients was changed, rolling from one side to the other, to foster the homogeneous distribution of blood within the pleural cavity. After instillation of autologous blood, the drainage was left watersealed without applying any suction.

Chest radiography was performed every day to confirm complete expansion of the residual lobe. The presence of air leakage was checked immediately after pleurodesis and every 12 hours during the following days until the air leak disappeared. The chest tubes were withdrawn 24 hours after the disappearance of the air leak, and the patients were subsequently discharged.

We compared the duration of blood patch, air leaks, and hospitalization between the 2 groups with 1-way analysis of variance. The results obtained in groups A and B were subsequently retrospectively compared with a series of 15 patients (group C; age $67 \pm 7.1$ years; 9 men $/ 6$ women; $\mathrm{FEV}_{1} 2.3 \pm 0.5 \mathrm{~L} / \mathrm{sec}$ ) who showed the presence of air leaks on the sixth postoperative day after pulmonary lobectomy but did not receive any additional treatment, with the exception of alternating suction and nonsuction drainage; in this group the duration of leakage was obviously compared after the sixth postoperative day.

\section{Results}

Groups A, B, and C were homogeneous for demographics and functional parameters. In group A we performed 4 right upper lobectomies, 3 middle lobectomies, 2 left upper lobectomies (histology: 5 adenocarcinomas and 4 squamous cell carcinomas); in group B we performed 4 right upper lobectomies, 1 middle lobectomy, 2 right lower lobectomies, and 3 left upper lobectomies (histology: 6 adenocarcinomas and 4 squamous cell carcinomas). In group $\mathrm{C}$ we performed 5 right upper lobectomies, 5 left upper lobectomies, 3 middle lobectomies, and 1 left and 1 right lower lobectomy (histology: 8 adenocarcinomas, 6 squamous cell carcinomas, and 1 mixed adenosquamous carcinoma). The air leakage stopped $2.3 \pm 0.6$ days after the procedure in group $\mathrm{A}$ and $1.5 \pm 0.6$ days after the procedure in group $\mathrm{B}$ $(P=.005)$. In group $C$ the air leakage disappeared $6.3 \pm$ 3.7 days after the sixth postoperative day. The difference between groups $\mathrm{A}$ and $\mathrm{C}$ and groups $\mathrm{B}$ and $\mathrm{C}$ was also statistically significant $(P=.0009$ and .0001 , respectively). The air leakage disappeared within 72 hours after pleurodesis in all patients in groups $\mathrm{A}$ and $\mathrm{B}$; however, in 8 of 12 patients $(66.7 \%)$ in group A the air leak stopped within 24 hours, but it never disappeared immediately after the instillation of blood; in the other 4 patients the leakage stopped within 72 hours. In 8 of the 13 patients $(61.5 \%)$ in group B the air leak stopped either immediately (5 cases) or within 12 hours ( 3 cases); the air leak disappeared within 48 hours (4 patients) and 3 days ( 1 patient) in the remaining 3 cases.

The chest tube was withdrawn in all patients 24 hours after the air leak stopped, and after another 24 hours all patients were discharged; for this reason the difference between these variables in the 3 groups was statistically significant. We did not observe any infection of the pleural cavity, early or late side effects, or operative mortality. Blood withdrawal did not cause any significative modification of the hemodynamics of the patients. In group C, 2 patients had atrial fibrillation and 1 patient had pneumonia in the residual lobe.

\section{Discussion}

The presence of an air leakage after pulmonary lobectomy is considered one of the most common problems in thoracic surgery. Almost all air leaks originating from the periphery of the lung stop within 24 to 48 hours from surgery, as soon as the residual parenchyma completely fills the pleural cavity and gets in touch with the parietal pleura. However, a number of patients still experience a prolonged hospitalization because of the persistence of this problem. A prolonged air leak is considered to be one that persists beyond the normal hospital stay (usually 5-7 days); it usually leads to prolonged hospitalization and increased costs and morbidity. ${ }^{12}$ Economic pressures to reduce the length of hospitalization results in several strategies, including discharging patients with air leaks and indwelling chest tubes, which makes hospital discharge an artificial end point. Thus, the end point defining the "persistence" of an air leak should be when and not where it stops.

Upper lobectomies have a higher incidence of postoperative air leaks ${ }^{13}$ because an apical space often remains, 
causing more difficult pleural synthesis and sealing. Persistent air leaks are reported to complicate $25 \%$ of the upper lobectomies and are the only complication in $81 \%$ of these patients. ${ }^{14}$ Rice and Kirby ${ }^{15}$ reported a $15.2 \%$ incidence of air leaks in a population of 197 patients undergoing major pulmonary resections; however, the air leak persisted for more than 14 days in only 3 of the patients (1.5\%). In a series of 674 lobectomies or lesser resections performed at 2 Canadian hospitals ${ }^{16}$ the incidence of peripheral air leaks was $4 \%$. Nagasaki and colleagues ${ }^{17}$ reported a prolonged air leak (7-20 days) occurring in 10 of 961 pulmonary resections for malignancy $(<1 \%)$, and all air leaks stopped spontaneously. In a review of 369 lobectomies, Keagy and colleagues $^{18}$ reported 16 prolonged air leaks (4.3\%). Significant risk factors are male gender and larger forced vital capacity (related to larger lungs with greater raw surfaces after lung resection), age and chronic obstructive pulmonary disease or other underlying lung diseases, a lower predicted $\mathrm{FEV}_{1}$ and $\mathrm{FEV}_{1} /$ forced vital capacity, and absence of interlobar fissures. ${ }^{15}$

Any tear in the residual lung parenchyma, either from aggressive traction or adhesions, could lead to a significant postoperative leakage. Thus, dissection of pleural adhesions and fissures is the major source of air leak after lobectomy or wedge resection. Intraoperative air leak prevention is the optimum approach. In particular, when the fissures are incomplete, direct dissection to connect them to the pulmonary vessels is required; electrocautery, ${ }^{19}$ argon beam coagulation,${ }^{20}$ laser, ${ }^{21}$ and stapling may be used. A recent development called "fissureless" surgery seems to be able to decrease the incidence of postoperative air leaks, ${ }^{22}$ avoiding any dissection in the fissure itself. The magnitude of the air leak certainly has some bearing on persistence. ${ }^{23}$

Prevention of air leaks certainly begins in the operating room and requires meticulous surgical technique, complete expansion of the residual lung, and, if necessary, reduction of the plural space with the creation of a pleural tent $^{24}$ and use of glues ${ }^{25}$ and reinforcement material on the suture line. ${ }^{26}$ However, notwithstanding these well-known methods, some patients still have this complication; when it occurs, a number of procedures may be used to solve the problem. Conservative approaches include a longer period of drainage; physiotherapy; pleurodesis with tetracycline, quinacrine, talcum, or silver nitrate; pneumoperitoneum; and the use of a Heimlich valve. ${ }^{1-7}$ These methods have produced encouraging results in selected settings, but none have definitively solved the problem.

Pleurodesis with an autologous blood patch to treat a persistent air leak after pneumothorax was first reported by Robinson, ${ }^{8}$ who described an $85 \%$ success rate in a series of 25 patients receiving 1 to 3 instillations of $50 \mathrm{~mL}$ of blood in the chest. These data were subsequently confirmed by other reports. ${ }^{9,10}$ The sealing effect of blood can be easily explained by the direct mechanical action of the fibrin produced by the patch and the inflammatory reaction resulting from the presence of blood in the pleural cavity, which may be the primary factor to induce adhesion between the visceral and the parietal pleural layers. However, although the effectiveness of this technique was evident, the amount of blood required was debated $(50-120 \mathrm{~mL}){ }^{11}$

With this technique, we obtained a $100 \%$ success rate in less than 24 hours in most of the patients, particularly when $100 \mathrm{~mL}$ of autologous blood was instilled; this result was obtained at a low cost and with no morbidity. There was no tension within the chest caused by blood clotting because of the technique we previously described (hooking the chest drain[s] up over a drip-stand and allowing air to escape while the blood pleurodesis remained within the chest). The chest tube was not occluded because it was flushed with $20 \mathrm{~mL}$ of normal saline to prevent this complication; this allowed us to avoid the tension pneumothorax described by other authors. ${ }^{27}$ Other complications were reported by other authors, that is, fever and colonization of the pleural fluid, ${ }^{9}$ but these were not observed in our study. Careful sterile manipulation of the system during the procedure should be stressed to avoid infectious complications.

Our study demonstrated the effectiveness of early pleurodesis with an autologous blood patch to treat air leaks after pulmonary lobectomy, with a clear advantage over a conservative suction-waterseal approach, although the study loses some strength with the retrospective analysis. Pleurodesis with $50 \mathrm{~mL}$ of blood is effective and allows closure of postoperative air leaks in a short period of time. However, pleurodesis with $100 \mathrm{~mL}$ of blood increases effectiveness and allows sealing in less than 24 hours in most of the patients.

Pleurodesis with an autologous blood patch, which can be included among common bedside surgical procedures, is easy to perform, safe, and effective, and does not add costs. It can be used as a first-line maneuver to solve this common and unpleasant problem.

We thank Dr Luca Voltolini from the University of Siena for suggesting the use of this technique several years ago.

\section{References}

1. Rice TW, Okereke IC, Blachstone HH. Persistent air leaks following pulmonary resection. Chest Surg Clin N Am. 2002;12:529-39.

2. De Giacomo T, Rendina EA, Venuta F, et al. Pneumoperitoneum for the management of pleural air space problems associated with major pulmonary resections. Ann Thorac Surg. 2001;72:1716-9.

3. Almassi GH, Haasler GB. Chemical pleurodesis in the presence of persistent air leak. Ann Thorac Surg. 1989;47:786-7.

4. Chechani V. Tetracycline pleurodesis for persistent air leak. Ann Thorac Surg. 1990;49:166-7.

5. Janzing HM, Derom A, Derom E, Derom F, Rosseel MT. Intrapleural quinacrine instillation for recurrent pneumothorax or persistent air leak. Ann Thorac Surg. 1993;55:368-71.

6. Baumann MH, Strange C. The clinician's perspective on pneumothorax management. Chest. 1997;112:822-8. 
7. Gallivan GJ. Pleurodesis and silver nitrate. Chest. 2001;119:1624.

8. Robinson CL. Autologous blood for pleurodesis in recurrent and chronic spontaneous pneumothorax. Can J Surg. 1987;30:428-9.

9. Lang-Lazdunski L, Coonar AS. A prospective study of autologous blood patch pleurodesis for persistent air leak after pulmonary resection. Eur J Cardiothorac Surg. 2004;26:897-900.

10. Rivas de Andrès JJ, Blanco S, de la Torre M. Postsurgical pleurodesis with autologous blood in patients with persistent air leak. Ann Thorac Surg. 2000;70:270-2.

11. Jones NC, Curray P, Kirk AJB. An alternative to drain clamping for blood pleurodesis. Eur J Cardiothorac Surg. 2005;27:935.

12. Varela G, Jimenez M, Novos N, Aranda JL. Estimating hospital costs attributable to prolonged air leak in pulmonary lobectomy. Eur J Cardiothorac Surg. 2005;27:329-33.

13. Miller JL Jr. Acute and delayed space problems following pulmonary resection. Chest Surg Clin North Am. 1996;6:615-21.

14. Abohoda A, Liu D, Brooks A, et al. Prolonged air leak following radical right upper lobectomy: an analysis of the incidence and possible risk factors. Chest. 1998;113:1507-10.

15. Rice TW, Kirby TJ. Prolonged air leak. Chest Surg Clin North Am. 1992;2:803-11

16. Deslauriers J, Ginsberg RJ, Dubois P, Beaulieu M, Goldberg M, Piraux M. Current operative morbidity associated with elective surgical resection for lung cancer. Can J Surg. 1989;32:335-9.

17. Nagasaki F, Flehinger BJ, Martini N. Complications of surgery in the treatment of carcinoma of the lung. Chest. 1982;82:25-9.
18. Keagy BA, Lores ME, Starek PKJ, Murray GF, Lucas CL, Wilcox BR. Elective pulmonary lobectomy: factors associated with morbidity and operative mortality. Ann Thorac Surg. 1985;40:349-52.

19. Cooper JD, Perelman M, Todd TR, et al. Precision cautery excision of pulmonary lesions. Ann Thorac Surg. 1986;41:51-3.

20. Rush VW, Schmidt R, Shoji, et al. Use of argon beam electrocoagulator for performing pulmonary wedge resections. Ann Thorac Surg. 1990;49:287-91.

21. Mineo TC, Ambrogi V, Pompeo E, et al. The value of the Nd:YAG laser for the surgery of lung metastases in a randomized trial. Chest. 1998:113:1402-7.

22. Cerfolio RJ, Bass C, Pask A. Predictors and treatment of persistent air leaks. Ann Thorac Surg. 2002;73:1727-30.

23. Cerfolio RJ, Bass C, Katholi CR. Prospective randomized trial compares suction versus water seal for air leaks. Ann Thorac Surg. 2001; 71:1613-7.

24. Robinson LA, Preksto D. Pleural tenting during upper lobectomy decreases chest tube time and total hospitalization days. J Thorac Cardiovasc Surg. 1998;115:319-27.

25. Fleisher AG, Evans KG, Nelems B, Finley RJ. Effect of routine fibrin glue use on the duration of an air leak after lobectomy. Ann Thorac Surg. 1990;49:133-4.

26. Venuta F, Rendina EA, De Giacomo T, et al. Technique to reduce air leaks after pulmonary lobectomy. Eur J Cardiothorac Surg. 1998;13: 361-4.

27. Williams P, Lang R. Tension pneumothorax complicating autologous "blood patch" pleurodesis. Thorax. 2005;60:1066-7. 